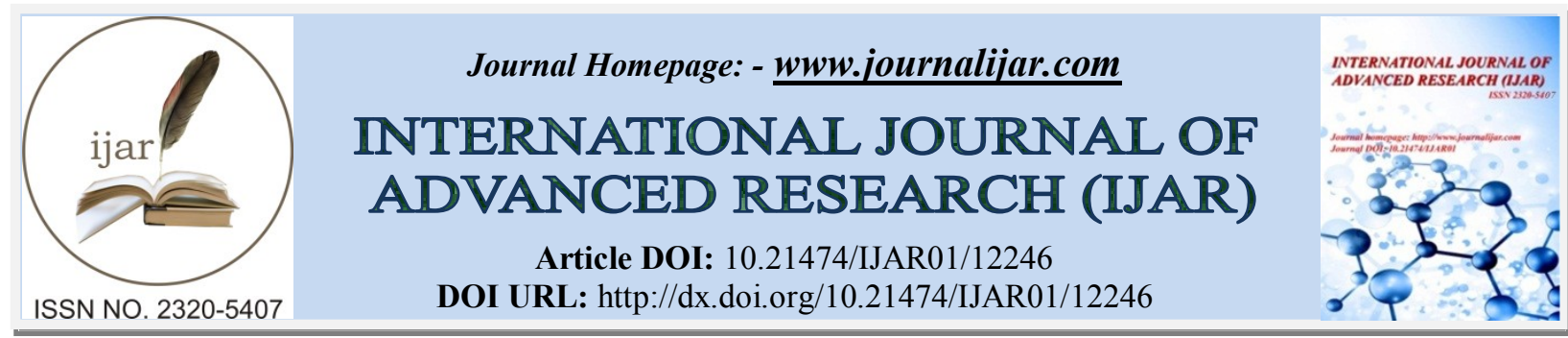

RESEARCH ARTICLE

\title{
MYTHS, ATTITUDE AND HEALTH SEEKING BEHAVIOR REGARDING MENTAL ILLNESS: SYNOPSIS OF ARTICLE REVIEW
}

\author{
Ms. Minu S. Nair \\ People's College of Nursing and Research Centre, Bhopal, M.P.
}

\section{Manuscript Info}

Manuscript History

Received: 31 October 2020

Final Accepted: 30 November 2020

Published: December 2020

\section{Abstract}

Mental Health is an important aspect of health. It includes emotional, social and psychological well being, nurturing mental health helps to prevent mental health issues to a great extent. Mental health greatly influences the quality of life just like physical health. In low- and middle-income countries, more than $75 \%$ of people with mental, neurological and substance-use disorders receive no treatment for their condition - due to stigma, discrimination, harsh legislation and humanrights issues. Mental health does not enjoy the parity as that of physical health. The objective of the review is to determine the myths, attitude and health seeking behavior prevalent among people across the globe. Therefore the studies from 2001 to 2020 are collected and reviewed.

Copy Right, IJAR, 2020,. All rights reserved.

\section{Introduction:-}

Mental health is "a state of psychological and emotional well-being where the individual has the realization of his or her abilities, strengths and weaknesses he or she can overcome the normal stressors of life and is capable of making contribution to his or her community. The prevalence of mental disorders in India ranges from 10 to 370 per 1000 population in several parts of the country and the rate is higher among females. The magnitude of mental health burden is not addressed in accordance to the kind of response it demands. At present, more than $33 \%$ of countries allocate less than $1 \%$ of their total health budgets to mental health and another $33 \%$ end up spending only $1 \%$ of their budgets on mental health. These research studies are reviewed so as to determine the mindset of people regarding mental illness around the world.

\section{Literature Related To Myths Towards Mental Illness:}

Gebrekidan Abbay A et.al (2018) carried out a study to examine the community health knowledge, perceived beliefs, and associated factors of mental distress (MD) in Mekelle city in Northern Ethiopia. The findings revealed that the likelihood of having MD was higher among the study participants who were female, employed, selfemployed, and daily alcohol and khat users. The results also showed that the level of mental health knowledge among the participants was low. Factors such as being male, having a higher level of education, and having strong levels of social support were found to be the independent predictors of good mental health and community mental health knowledge.

HB Usman Shah et.al.(2018) carried out a comparative cross-sectional study to assess the perceptions about treatment of psychiatric disorders by faith healers and psychiatrists among general public of urban and rural areas of Rawalpindi district.The findings of the study revealed that (74\%) of people from urban areas tend to seek treatment from psychiatrists as compared to (55\%) of those living in rural areas who choose and believe in methodology and 
treatment offered by faith healers. Lack of education, poor socioeconomic status, high treatment cost and most importantly false beliefs were the major contributory factors for the inclination of rural people towards faith healers.

Benti M et.al (2016) conducted a study to assess the community perception towards mental illness among residents of Gimbi Town, Western Ethiopia. Community. Significant proportions of the community in Gimbi town were found to have poor perception of mental illness. Poor perception is common among old aged, less educated, private workers, those unable to access mental health information, and those with no family history of mental illness. Mental health education on possible causes, treatment options, and possible outcome of treatment to the community is required.

Grover S et.al.(2014) conducted a study to assess the relationship between first treatment contact and supernatural beliefs among caregivers of patients with Schizophrenia attending a tertiary care hospital situated in North India. According to the findings of the study the first treatment contact was faith healers in $23.8 \%$ of the patients. (74.6\%)of the caregivers believed that patients' symptoms are due to supernatural belief like sorcery / witchcraft, ghosts, spirit intrusion, divine wrath, planetary influences, evil spirits, and bad deeds in previous life. It was observed that those who contacted faith healers for their patients' treatment had significantly higher attribution of the symptoms to supernatural causes.

Poreddi V et.al (2014) carried out a cross-sectional descriptive survey to assess the mental health literacy among caregivers of persons with mental illness. The findings depicted that $69 \%$ of the participants agreed that mental illness was caused by genetic inheritance followed by substance abuse (64\%). However, $45.9 \%$ felt that mental illness is because of personal weakness. Majority of the participants (68.4\%) agreed that anyone could suffer from mental illness. However, $61.5 \%$ of them agreed that people with mental health problems are largely to blame for their condition and are usually dangerous $(\mathbf{n}=87,54 \%)$. The participants expressed mixed opinions towards people with mental illness. While $47.8 \%$ of them agreed that people with mental illness could get married, $54.7 \%$ of them disapproved to marry a person with mental illness. Nearly two-thirds $(62.2 \%)$ believed that people with mental illness have the same rights as anyone else. However, 55.9\% would not want people to know if they had a mental illness and feel ashamed if a family member had a mental illness.

Kishore J et .al (2011) conducted a cross-sectional study from urban and rural communities of Delhi and 76 medical professionals working in different organizations in Delhi to assess the myths, beliefs and perceptions about mental illness. The findings of the study revealed that $(33.9 \%$ rural, $8.6 \%$ urban, $1.3 \%$ professionals $)$ believed that the mental disorders were because of loss of semen or vaginal secretions, less sexual desire (23.7\% rural, $18 \%$ urban), excessive masturbation (15.3\% rural, 9.8\% urban), God's punishment for their past sins (39.6\% rural, 20.7\% urban, $5.2 \%$ professionals), and polluted air (51.5\% rural, $11.5 \%$ urban, $5.2 \%$ professionals). Majority of people (37.7\%) were from joint families than from nuclear families $(26.5 \%)$ believed that sadness and unhappiness lead to mental disorders. $34.8 \%$ of the rural subjects and $18 \%$ of the urban subjects believed that children do not suffer from mental disorders. $40.2 \%$ in rural areas, $33.3 \%$ in urban areas, and $7.9 \%$ professionals believed that mental illnesses are untreatable. Many believed that psychiatrists are eccentric ( $46.1 \%$ rural, $8.4 \%$ urban, $7.9 \%$ professionals), tend to know nothing, and do nothing (21.5\% rural, $13.7 \%$ urban, $3.9 \%$ professionals), while $74.4 \%$ of rural subjects, $37.1 \%$ of urban subjects, and $17.6 \%$ professionals did not know that psychiatry is a branch of medicine. Majority of people in rural areas as compared to people from urban areas believed that keeping fast or seeking treatment from a faith healer can cure them from mental illnesses, whereas $11.8 \%$ of medical professionals believed the same.

\section{Literature related to attitude towards mental illness:}

Anis $\mathrm{S}$ et al (2020) carried a study to assess the knowledge and attitude of adolescents in $9^{\text {th }}$ to $12^{\text {th }}$ classes in high schools toward people with schizophrenia. The descriptive, cross-sectional study was conducted in 4 schools as part of a schizophrenia awareness program. A self-report questionnaire was administered with sections containing case vignette-based knowledge and attitude toward schizophrenia. Chi-square and "t"-test were done to find the association between demographic characteristics, knowledge level, and attitude. Of 1540 students, about half of all respondents had average knowledge and only $10.5 \%$ students had a good knowledge score. Although knowledge level of boys and girls was similar, boys had more positive attitude toward people with schizophrenia as compared to girls. Good knowledge was associated with less distancing with person with schizophrenia. About $45 \%$ adolescents believed that people with schizophrenia are more prone to violence. 
Kaur $\mathbf{H}$ et.al (2019) carried out a study to assess the attitude toward mental illness among adolescents in New Delhi. The findings suggested an overall positive attitude on separatism, benevolence, and stigma subscale and a negative attitude toward stereotyping, restrictiveness, and pessimistic prediction. No significant difference was observed in the attitudes of adolescents from both the categories.

Jilowa CS et al.(2018) carried out a cross sectional comparative study to assess the attitude of medical students with different years of exposure to medical education, toward psychiatry as a specialty. The study was conducted at JLN medical College, Ajmer.Only five second-year (5\%) and two intern (1.8\%) students affirmatively indicated to choose psychiatry as a career choice, while $73 \%$ denied choosing psychiatry as a specialty.

Basu Rivu et al (2017) conducted an observational, descriptive study with cross-sectional design to assess the knowledge, attitude, and practice regarding mental health illnesses in Amdanga block, West Bengal. CAMI questionnaire was used to collect the data. The findings showed that $94.9 \%$ were willing to live with a person with mental illness. $14.9 \%$ has actually done so. Health-care seeking behavior showed that $19.2 \%$ would prefer a GP in case of any mental illness. $78.1 \%$ reported that they are prone to violence. However, $71 \%$ believed that it can be cured through medication. Regarding fear about mental illness, $52.5 \%$ of population still believed that it would be foolish of a woman to marry a man who has suffered from mental illness even though he seems to be fully recovered and $90 \%$ supported that mentally ill patients need to be responsibly looked after, and a far more tolerant attitude toward people with mental illness is needed to be adopted. Integration showed a good response with $77.4 \%$ said that residents have nothing to fear from people coming into their neighborhood to obtain mental health services. However, $62.1 \%$ still believed that mental illness is caused due to the lack of willpower.

Pang S et al.(2017) conducted a cross sectional study to assess the stigma and adolescent attitudes towards serious mental illness and social tolerance in a multiethnic population of Singapore. About a quarter of the students (22.6\%) reported that they have participated in mental health awareness campaigns while nearly half $(44.5 \%)$ associated pejorative words and phrases with the term mental illness. Misconceptions and negative attitudes towards mental illness was common, highlighting the need for effective stigma reduction campaigns.

Aruna G et.al.(2016) conducted a descriptive, cross-sectional type of study to identify the perception, knowledge, and attitude towards mental disorders and psychiatry among medical undergraduates in Karnataka. Less than half of the participants $(46.03 \%, \mathbf{n}=186)$ considered psychiatric disorders to be legitimate medical disorders, while the rest either disagreed $(34.9 \%, \mathbf{n}=141)$ or were not sure $(19.05 \%, \mathbf{n}=77)$. When asked whether people in contact with psychiatric patients would behave strangely, $60.3 \%(\mathbf{n}=244)$ students did not believe so, while the rest either believed this to be true or were unsure. Around $49.7 \%$ of students believed patients with psychiatric disorders would not be productively employed by others even after recovery and $56.6 \%$ of them objected to the possibility of their own close relative marrying a person with a psychiatric disorder. Only $40.9 \%$ of students felt comfortable talking to psychiatric patients. The notion that older people were less prone to psychiatric disorders was found in $42.07 \%$ of students, while $51.2 \%$ believed that children do not suffer from any kind of psychiatric problem. A considerable proportion of students, however, did not consider decreased libido $(43.06 \% ; \mathbf{n}=174)$, excessive masturbation $(46.03 \%$, or $\mathbf{n}=186)$, or a hectic lifestyle $(52.7 \%, \mathbf{n}=213)$ to be risk factors. Majority of the students $(52.9 \%, \mathbf{n}=$ 214) disagreed on causes like God's punishment for past sins, poor nutrition $(54.9 \%, \mathbf{n}=222)$, air pollution $(68.8 \%, \mathbf{n}=278)$, or loss of semen/genital fluids $(57.4 \%, \mathbf{n}=232)$.

A Risal et.al (2013) conducted a study to assess the attitude toward mental illness and psychiatry among the medical students and interns in a medical college at Dhulikhel Hospital. Among the total 159 subjects, 44 (27.7\%) were interns. Most of the subjects showed neutral attitude towards all the scoring items; though there were a few significant differences in mean scores of some items in group wise comparison.

E Coppens et.al (2013) conducted a study to assess the public attitudes toward depression and help-seeking in four European countries namely Germany, Hungary, Ireland, and Portugal .A survey was conducted on a sample size of 4011.The participants exhibited a moderate level of personal stigma toward depression and a remarkably higher level of perceived stigma. More negative attitudes were found in Hungary and were associated with male gender, older age, lower educational level and living alone. The personal stigma was due to low openness to and less perceived value of professional treatment. 
Mansour Hamdan AM et al (2009) carried out a study to examine Jordanian mental health nurses' attitudes toward mental illness and patients with mental illness.About $60 \%$ of the mental health nurses believed that patients with mental illness were dangerous, immature, dirty, cold hearted, harmful, and pessimistic. In only two descriptions-being polite and adult-did nurses have positive perception about patients with mental illness. Majority of the nurses $70 \%$ of them were proud to be a mental health nurse. Age and gender were found to be the significant influential factors in determining the nurses' attitudes or satisfaction.

\section{Literature related to health seeking behavior regarding mental illness:}

Gabra R et.al(2020) carried out a study to assess the knowledge, attitude and health-seeking behavior among family caregivers of mentally ill patients at Assiut University Hospitals. The studied caregivers had low scores of knowledge and attitude towards mental illness. Age of the caregivers, their education, and the type of first consulted care and aggressive behavior of the mentally ill relatives were the significant predictors of caregivers 'knowledge and attitude towards mental illness. The majority of caregivers $(80.2 \%)$ sought advice for the first time from traditional healers. Traditional healers referred only $16.4 \%$ of caregivers of mentally ill relatives to psychiatric care. The findings revealed that caregivers had poor knowledge and a negative attitude towards mental illness.

Younis M et.al (2019) carried out a study in Iraq to ascertain the role of faith healers in the treatment of psychiatric illnesses by exploring the percentage of patients attending those healers. Among the total 482 cases; 279 (57\%) reported going to faith healers (FHs) at any time before, during, or after a psychiatric consultation. Of those, $84.6 \%$ reported visiting FHs less than 10 times, while $15.4 \%$ went 10 times or more; $36.9 \%$ still believe that the treatment of FHs is accepted or even good (21.5\%), while $30.9 \%$ realized that it is useless, and $10.7 \%$ think it is bad. No association was found between going to FHs and patient age or gender, while there was a significant association with marital status $(\mathrm{p}<0.02)$ and with education $(\mathrm{p}<0.001)$. Patients with schizophrenia/psychosis or bipolar disorders visited FHs significantly more often than those with other diagnoses. Faith healing is prevalent in Iraq and FHs may overwhelm the role of psychiatrists in treating mental illnesses. Sincere efforts are needed to help build public awareness and to improve accessibility and utilization of mental health services for this vulnerable group.

Upadhyaya S et.al (2018) carried a study to assess socio-cultural factors and patterns of help-seeking behavior of psychiatric patients in rural sub-Himalayan region.In this study of 250 patients, psychiatrists were chosen as first help by 98 (39\%), faith healers by 84 (34\%), and general medical practitioners (GMPs) by 68 (27\%) patients. Mean "years of education" of patients in psychiatrist group, faith healer group, and GMP group were 9.98, 8.81, and 7.99, respectively $(\mathbf{P}=0.08)$. Mean "years of education" of decision makers for these groups were 11.64, 8.36, and 10.93, respectively $(\mathbf{P}<0.001)$. Time required in reaching psychiatric facility form the residence of patient was maximum in those who consulted faith healers first compared to those who consulted psychiatrist $(\mathbf{P}<0.001)$ or GMP $(\mathbf{P}<$ 0.01). Expenses on faith healers were significantly high compared to GMPs $(\mathbf{P}<0.001)$. Psychiatrists, faith healers, and GMPs were equally chosen as first help for psychiatric illness. Education of decision maker and accessibility affect help-seeking behavior significantly. Faith healers were more expensive than GMPs.

Picco L et.al. (2018) conducted a cross sectional survey study among 3006 Singapore residents between the age of 18-65 years to assess the association between recognition and help-seeking preferences and stigma towards people with mental illness. Recognition was also associated with increased odds of promoting approach for aid from a psychiatric hospital for dementia, depression and schizophrenia, while there was also an increased inclination to seek help from a psychologist and psychiatrist for depression. Recognition was associated with low personal and perceived stigma for OCD and low personal stigma for schizophrenia, however, increased odds was found of social distancing for dementia.

Anusha K et.al (2017) conducted a study to assess the help-seeking behaviors in the relatives of mentally Ill persons at a Tertiary Care Hospital in Hyderabad, Telangana. The findings revealed that out of a total of 100 patients, 25 and 28 subjects in the low and high help-seeking groups, respectively, were included in the study. In the low helpseeking group, drug compliance was good and caregivers' education level was higher compared to the high helpseeking group. High help-seeking group was characterized by higher scores of hope and compassion on reactions to mental illness scale and the coping mechanisms of humor, denial, use of instrumental and emotional support, acceptance, and planning were frequently used. There is a need to develop awareness about mental illness in the general population and improve the available social support systems to the patients with mental illness and their family members. The help-seeking behaviors could be improved by training the personnel at primary health centers about the treatment of mental illness and importance of drug compliance and regular follow-up. 
Burns K.J et.al (2014) conducted a systematic review and Meta -analysis on traditional and religious healers in the pathway to care for people with mental disorders in Africa. Electronic databases were searched for the period from January 1990 to February 2014. Quality assessment of included studies was conducted the SAQOR tool.Based on the findings it was concluded that approximately half of the individuals seeking formal health care for mental disorders in Africa, choose traditional and religious healers as their first care provider. Previous reports suggest that this choice is associated with delays in accessing formal mental health services.

Julie S et.al (2014) conducted a study to assess the perception of traditional healing for mental illness in Gujarat. A total of 49 individuals were interviewed in July 2013 at Dhiraj General Hospital and in 8 villages surrounding Vadodara. The result revealed that participants treated by both a doctor and a healer reported they overwhelmingly would recommend a doctor over a healer. Almost all who were treated with medication saw an improvement in their condition. Many subjects felt that traditional healing can be beneficial and believed that patients should initially go to a healer for their problems. Participants were largely dissatisfied with their experiences with traditional healers, but healing is still an incredibly common first-line practice in Gujarat because healers are such integral parts of their communities and are very commonly sought out for treatment.

Goyal M et al (2012) conducted a study to assess effect of an educational booklet on knowledge and attitude regarding major depressive disorder in medical students in Delhi. The findings revealed that in the pretest phase only $71 \%$ of students had knowledge about depression, which increased to $88 \%$ in post test phase ( $\mathrm{p}=0.01$ ). Most common reasons for not seeking help were thinking that there is lack of understanding by other people about the depression (63\%), lack of confidentiality (49\%), social stigma (30\%), fear of rejection $(26 \%)$ and time constraints $(6 \%)$. Majority of students accepted the booklet for their understanding about depression where $63 \%$ considered that it improved their knowledge to great extent.

Naik S et.al (2012) carried a study aimed to describe and compare the help-seeking behaviors among caregivers of psychotic patients visiting psychiatric clinics at two distinct cities of India. Supernatural forces were held responsible by $40 \%$ of the Bilaspur sample in contrast to $8 \%$ in New Delhi sample. Faith-healers were initial contacts for $56 \%$ and $64 \%$ of sample, respectively, at New Delhi and Bilaspur. Faith-healers followed by a psychiatrist formed the commonest pathway of care at both centers ( $32 \%$ and $36 \%$, respectively).

Tanskanen S et.al (2011) carried out a qualitative a study to assess the Service user and carer help seeking experiences for a first episode of psychosis in UK. The findings revealed that help was very often not sought until crisis point, inspite of experiencing prior distress. The person experiencing symptoms was often the last to recognise them as mental illness. In an urban UK setting, those included, workers in non-health community organisations were frequently ready to provide help-seeking could not do so due to lack of skills, time or knowledge to do so.

Mishra $\mathbf{N}$ et al (2011) carried out a study to identify Help-seeking behavior of patients with mental health problems visiting a tertiary care center in north India. The findings revealed that psychiatrists were the first choice in $45 \%$ of the cases followed by non-psychiatric physicians and religious faith healers. $44 \%$ patients had consulted a nonpsychiatric physician in the first instance, whereas $8 \%$ went to traditional faith healer and $2.5 \%$ consulted an alternative medicine practitioner. $51 \%$ of the patients sought help from a traditional faith healer at some time during the course of their illness, whereas more than $80 \%$ consulted a non-psychiatric physician at some time. $41 \%$ had visited a psychiatrist outside the institute before coming to our setting, and $7 \%$ had been to an alternative medicine practitioner during the course of illness. Interestingly, $86 \%$ of the patients had consulted a psychiatrist by their second consultation, although some of them might have changed their health provider later.

Segal DL et.al (2005) conducted a cross-sectional study to assess the beliefs about mental illness and willingness to seek help. Participants completed the Beliefs Toward Mental Illness Scale and the Willingness to Seek Help Questionnaire. Older adults had generally similar perceptions of mental illness as younger adults except that older adults were more likely to perceive the mentally ill as being embarrassing and having poor social skills. Older adults also did not report a lower willingness to seek psychological help. Correlational analyses showed that, among older adults, increases in negative attitudes about mental illness (specifically, the view that the mentally ill have poor interpersonal skills) are associated with decreases in willingness to seek psychological services. The study also focused on the need to assess the help seeking behaviour of psychiatric patients and factors associated with it. 


\section{Conclusion:-}

The literature review emphasizes that mental illness is associated with endless stigma, all the studies conducted strongly indicate that people are reluctant to talk about mental health issues and there is lack of awareness. There has to be a robust system and an open environment in place to help curb this stigma and eradicate it fully. It should be a collective effort from every individual in the society to bring about this change where in mental health issues will no longer remain unaddressed.

\section{References:-}

1. Mental health: strengthening our response [Internet]. Who.int. 2020 [cited 13 January 2020]. Available from: https://www.who.int/news-room/fact-sheets/detail/mental-health-strengthening-our-response

2. WHO | Mental disorders affect one in four people [Internet]. Who.int. 2001 [cited 16 January 2020]. Available from: https://www.who.int/whr/2001/media_centre/press_release/en/

3. Venkataswamy M. Reddy C. Prevalence of mental and behavioural disorders in india : a meta-analysis [Internet]. PubMed Central (PMC). 1998 [cited 16 February 2020]. Available from: https://www.ncbi.nlm.nih.gov/pmc/articles/PMC2965838/

4. Gebrekidan Abbay A, Tibebe Mulatu A, Azadi H. Community Knowledge, Perceived Beliefs and Associated Factors of Mental Distress: A Case Study from Northern Ethiopia. International Journal of Environmental Research and Public Health [Internet]. 2018;15(11):2423. Available from: https://www.ncbi.nlm.nih.gov/pmc/articles/PMC6265946/

5. Shah HB, Atif I, Nabeel M, Qureshi H, Sadiq SM, Ahmed W, Raheem A, Bukhari H. Perceptions about treatment of psychiatric disorders by faith healers/psychiatrists among general public of urban and rural areas of rawalpindi district. Journal of Ayub Medical College Abbottabad. 2018 Mar 16;30(2):223-8.

6. Benti M, Ebrahim J, Awoke T, Yohannis Z, Bedaso A. Community Perception towards Mental Illness among Residents of Gimbi Town, Western Ethiopia. Psychiatry Journal [Internet]. 2016:1-8. Available from: https://www.hindawi.com/journals/psychiatry/2016/6740346/

7. Poreddi V, BIrudu R, Thimmaiah R, Math S. Mental health literacy among caregivers of persons with mental illness: A descriptive survey. Journal of Neurosciences in Rural Practice [Internet]. 2015;6(03):355-360. Available from: https://www.ncbi.nlm.nih.gov/pmc/articles/PMC4481790/

8. Kishore J, Jiloha R, Gupta A, Bantman P. Myths, beliefs and perceptions about mental disorders and healthseeking behavior in Delhi, India. Indian Journal of Psychiatry [Internet]. 2011;53(4):324. Available from: https://www.ncbi.nlm.nih.gov/pmc/articles/PMC3267344/

9. Anis SS, Vankar GK, Kansal KR, Jambusarwala TN, Gor VP. Knowledge and attitudes toward schizophrenia among high school adolescents. Ann Indian Psychiatry [serial online] 2020 [cited 2020 Jul 30];4:40-7. Available from: http://www.anip.co.in/text.asp?2020/4/1/40/285505

10. Kaur H, Sharma S, Vallamkonda OR. Attitude toward mental illness among adolescents: A hospital-based study. Indian J Soc Psychiatry [serial online] 2019 [cited 2020 Jul 30];35:193-200. Available from: http://www.indjsp.org/text.asp?2019/35/3/193/268336

11. Basu R, Sau A, Saha S, Mondal S, Ghoshal PK, Kundu S. A study on knowledge, attitude, and practice regarding mental health illnesses in Amdanga block, West Bengal. Indian J Public Health [serial online] 2017 [cited $2020 \mathrm{Jul}$ 30];61:169-73. Available from: http://www.ijph.in/text.asp?2017/61/3/169/214810

12. Pang S, Liu J, Mahesh M, Chua B, Shahwan S, Lee S et al. Stigma among Singaporean youth: a cross-sectional study on adolescent attitudes towards serious mental illness and social tolerance in a multiethnic population. BMJ Open [Internet]. 2017;7(10):e016432. Available from: https://bmjopen.bmj.com/content/7/10/e016432

13. Aruna G, Mittal S, Yadiyal M, Acharya C, Acharya S, Uppulari C. Perception, knowledge, and attitude toward mental disorders and psychiatry among medical undergraduates in Karnataka: A cross-sectional study. Indian Journal of Psychiatry [Internet]. 2016;58(1):70. Available from: https://www.ncbi.nlm.nih.gov/pmc/articles/PMC4776586/

14. Risal A, Sharma P, Sanjel S. Attitude towards Mental illness and Psychiatry among the Medical students and Interns in a University Medical College. Journal of Nepal Medical Association [Internet]. 2013;52(190). Available

from: https://www.researchgate.net/publication/257938545_Attitude_towards_Mental_Illness_and_Psychiatry_among the_Medical_Students_and_Interns_in_a Medical_College

15. Coppens E, Van Audenhove C, Scheerder G, Arensman E, Coffey C, Costa S et al. Public attitudes toward depression and help-seeking in four European countries baseline survey prior to the OSPI-Europe intervention. 
Journal of Affective Disorders [Internet]. 2013;150(2):320-329. Available from: https://pubmed.ncbi.nlm.nih.gov/23706876

16. Hamdan-Mansour A, Wardam L. Attitudes of Jordanian Mental Health Nurses Toward Mental Illness and Patients with Mental Illness. Issues in Mental Health Nursing [Internet]. 2009;30(11):705-711. Available from: https://www.researchgate.net/publication/38052625_Attitudes_of_Jordanian_Mental_Health_Nurses_Toward Mental_Illness_and_Patients_with_Mental_Illness

17. Gabra $\overline{\mathrm{R}}$, Ebrahim $\overline{\mathrm{O}}$, Osman D, Al-Attar G. Knowledge, attitude and health-seeking behavior among family caregivers of mentally ill patients at Assiut University Hospitals: a cross-sectional study. Middle East Current Psychiatry [Internet]. 2020;27(1). Available from: https://mecp.springeropen.com/articles/10.1186/s43045-0200015-6

18. Younis M, Lafta R, Dhiaa S. Faith healers are taking over the role of psychiatrists in Iraq. Qatar Medical Journal [Internet]. 2020;2019(3). Available from: https://www.ncbi.nlm.nih.gov/pmc/articles/PMC6883745/

19. Upadhyaya S, Raval C, Sharma D. The sociocultural factors and patterns of help-seeking among patients with mental illness in the sub-Himalayan region. Industrial Psychiatry Journal [Internet]. 2018;27(2):279. Available from: https://www.ncbi.nlm.nih.gov/pmc/articles/PMC6592195/

20. Picco L, Abdin E, Pang S, Vaingankar J, Jeyagurunathan A, Chong S et al. Association between recognition and help-seeking preferences and stigma towards people with mental illness. Epidemiology and Psychiatric Sciences [Internet]. 2016;27(1):84-93. Available from: https:/www.ncbi.nlm.nih.gov/pmc/articles/PMC6998888/

21. Anusha K, Bogaraju, Anand, Usha L. Help-seeking behaviors in the relatives of mentally Ill persons at a Tertiary Care Hospital. Indian J Soc Psychiatry [serial online] 2017 [cited 2020 Jul 30];33:250-5. Available from: http://www.indjsp.org/text.asp?2017/33/3/250/214597

22. Burns J, Tomita A. Traditional and religious healers in the pathway to care for people with mental disorders in Africa: a systematic review and meta-analysis. Social Psychiatry and Psychiatric Epidemiology [Internet]. 2014;50(6):867-877. Available from: https:/www.ncbi.nlm.nih.gov/pmc/articles/PMC4442066/

23. Goyal M, Kohli C, Kishore J, Jiloha R. Effect of an Educational Booklet on Knowledge and Attitude Regarding Major Depressive Disorder in Medical Students in Delhi. International Journal of Medical Students [Internet]. 2013;1(1):16-23. Available from: https://www.researchgate.net/publication/237334502_Effect_of_Educational_Booklet_on_Knowledge_and_Att itude_Regarding_Major_Depressive_Disorder_in_Medical_Students_in_Delhi

24. Naik S, Pattanayak S, Gupta C, Pattanayak R. Help-seeking Behaviors Āmong Caregivers of Schizophrenia and other Psychotic Patients: A Hospital-based Study in Two Geographically and Culturally Distinct Indian Cities. Indian Journal of Psychological Medicine [Internet]. 2012;34(4):338. Available from: https:/www.ncbi.nlm.nih.gov/pmc/articles/PMC3662130/

25. Tanskanen S, Morant N, Hinton M, Lloyd-Evans B, Crosby M, Killaspy H et al. Service user and carer experiences of seeking help for a first episode of psychosis: a UK qualitative study. BMC Psychiatry [Internet]. 2011;11(1):157. Available from: https://www.researchgate.net/publication/51683968_Service_user_and_carer_experiences_of_seeking_help_for a_first_episode_of_psychosis_A_UK_qualitative_study

26. $\overline{\text { Mishra }} \overline{\mathrm{N}}$, Nagpal SS, Chadda RK, Sood M. Help-seeking behavior of patients with mental health problems visiting a tertiary care center in North India. Indian J Psychiatry [serial online] 2011 [cited 2020 Oct 26];53:234-8. Available from: https://www.indianjpsychiatry.org/text.asp?2011/53/3/234/86814

27. Segal D, Coolidge F, Mincic M, O'Riley A. Beliefs about mental illness and willingness to seek help: A crosssectional study. Aging \& Mental Health [Internet]. 2005;9(4):363-367. Available from: https://www.uccs.edu/Documents/dsegal/Beliefs-about-mental-illness-Aging-and-Mental-Health-2005.pdf. 